NBER WORKING PAPER SERIES

\title{
CAUSALITY AND INNOVATIONS BETWEEN FER'TILITY AND INFANT MORTALITY
}

Tadashi Yamada

Working Paper No. 1093

NATIONAL BURFAU OF ECONOMIC RESEARCH 1050 Massachusetts Avenue

Cambridge MA 02138

March 1983

The research reported here is part of the NBER's research program in Health Economics. Any opinions expressed are those of the author and not those of the National Bureau of Economic Research. 


\section{CAUSALITY AND INNOVATIONS BETWEEN}

FERTILITY AND INFANT MORTALITY

\section{ABSTRACT}

The main issue of this paper is to study the sign and direction of causality between two demographic variables the fertility rate and the infant mortality rate - by using time series methodology. It is shown that a fall in fertility will decrease infant mortality below its normal level. It is also shown that fertility and infant mortality are not mutually independent but jointly determined. Therefore, when one constructs a model of the relationship between fertility and infant mortality, it is suggested that one should estimate a fertility equation in which infant mortality rate is an endogenous variable in a simultaneous equations system and vice versa.

Tadashi Yamada National Bureau of Economic Research 269 Mercer Street, 8th Floor New York, New York 10003 (212) 598-7098 


\section{CAUSALITY AND INNOVATIONS BETWEEN}

\section{FERTILITY AND INFANT MORTALITY}

\section{Tadashi Yamada*}

The relationship between fertility and infant mortality plays an important role both in the Malthusian theory of population and in the modern economic theory of population. In the Malthusian theory an increase in the fertility rate is expected to cause an increase in the infant mortality rate with a lag. In the modern economic theory a reduction in the infant mortality rate is expected to have an impact on the fertility rate with a lag, although the sign of the relationship is ambiguous. These two theories suggest the relationship between fertility and infant mortality reflects lagged causality in both directions. Therefore, it is natural to apply time-series causality tests developed by Granger and sims to fertility and infant mortality. The importance of such a study is underscored by Williams (1975) who states: "those who seek to explain fertility treat mortality as an exogenously given explanatory variable. On the other hand, those who seek to explain mortality view fertility as an exogenously given independent variable." 1 Hence, many existing estimates of fertility demand functions and infant survival production and demand functions are marred by simultaneous equation bias. 
In this paper, I apply time series causality tests to annual data for the United States, the Netherlands, Japan, and Israel. The observation periods are: 1920-1979 for the United States; 1936-1974 for the Netherlands; 1947-1977 for Japan; and 1940-1974 for Israel. It may be argued that such a study may be more relevant to underdeveloped countries. But, although infant mortality rates are relatively low in the four countries at issue, they have not reached some "minimum level." In particular, infant mortality rates in these four countries have fallen rapidly, even in the last part of the period at issue. The infant mortality rate in the United States declined at an annually compounded rate of 4.4 percent per year from 1964 to 1977 , according to Grossman and Jacobowitz (1981). The infant mortality rates in the Netherlands and Japan declined about 54 percent and 73 percent from 1955 to 1974 , respectively. 2

The four countries are selected for study because they exhibit some similarities but,also exhibit some interesting differences. Currently all four countries can be characterized as developed economies, but the United States and the Netherlands were at more advanced stages of development at the beginning of the period than Japan and Israel. The Netherlands is a more homogeneous country than the United States. It has already been indicated that infant mortality rates have declined dramatically in all four countries. 
On the other hand their fertility rates have exhibited somewhat different patterns. The fertility rate in the United states reached about 123 per 1,000 women aged $15-44$ in 1957 and fell rapidly since, to 68 in 1974 . The rate in the Netherlands has ranged between 65 and 80 per 1,000 women aged 10-49 from 1950 through 1970. In Japan, the fertility rate surprisingly declined from about 109 per 1,000 women aged 10-49 in 1947 to about 51 in 1961 and then slightly increased except 1966 (the year named "Hinoeuma"). 3 As an exceptional example, the fertility rate in Israel increased from about 94 per 1,000 women aged 10-49 in 1955 to 97 in 1974. These similarities and differences should be useful in illuminating the nature of the relationship between fertility and infant mortality.

One may treat infant mortality as one of the nonmarket goods produced according to a given household production function by using parents' time and market goods as the inputs (Becker and Lewis 1974; De Tray 1974; and willis 1974). The degree to which each infant in the household is exposed to its death might depend on the parents' prenatal care as well as the care after its birth. The parents can, by devoting time and medical care and providing nutritious food to children, improve their health status. The amounts they can afford to allocate depend on income and costs, 
e.g., husband's and wife's wage rates, medical cost and the price of food. Hence, they can directly influence the level of children's health through their employment and consumption decisions. Also, children's health is indirectly influenced by government programs such as subsidized medical care and family planning (Grossman and Jacobowitz 1981) and the enviromental conditions in which the parents and their children live, e.g., sanitation, water supply, transportation, urbanization and so on (Butz, DaVanzo, and Habicht 1982). These above points will explain why infant mortality, in addition to fertility, should be considered as a nonmarket good, which is jointly determined with fertility by household behavior.

A recent population study by Eckstein, Schultz and Wolpin (1981) indicates that fertility and infant mortality were causally related with each other in Swedish data during the period of $1870-1955$, reflecting less significant influence on those demographic variables of economic and meteorological variables. 4

In general, the explanations of causality from infant mortality to fertility are based on economic, biological, and psychological reasons. In the modern economic theory of population, i.e., the theory of household production, a particular household utility function is assumed to consist of its desired number of surviving children and a vector of consumption goods in the household. 
The desired number of surviving children is the product of number of births and the survival probability during a given period. This theory predicts that, if the parents can revise their desired number of surviving children in response to a reduction in infant mortality, whether they increase (or decrease) their number of births will depend on their own gross price elasticity of demand for surviving children. Therefore, the sign of association between fertility and infant mortality is ambiguous. In their response to a fall in infant mortality rate, the parents may use hoarding and replacement strategies to attain their desired number of surviving children. Olsen (1980) found direct replacement of modest magnitude for the colombian data and indicated that each death produces 0.2 new births on the average while fertility hoarding may raise the total fertility to roughly one-half birth per death.

From a biological perspective, in a society in which a large number of mothers breast-feed their children, a reduction in infant mortality makes the period of mother's lactation longer, and as the consequence, delays the next conception (Heer 1966; Heer and Smith 1968; Knodel 1968; and Preston 1978). From a psychological perspective, people in a given society may desire to reduce their family size in the process of social and economic development. Davis (1945) explains the effect of economic development on 
the family size such that as the economy develops, people in the society become competitive and individualistic in the urban society. A large family can be considered to be, not a blessing, but a handicap. Consequently, parents have an incentive to reduce their fertility in accordance with their optimal family size as the infant mortality rate falls due to the economic development. Lee (1981) found, in the English vital rates from 1540 to 1840 , that marital fertility fluctuations were substantially explained by the fluctuations in mortality, temperature, and prices (wheat prices as the indicator of economic conditions).

on the other hand, causality from fertility to infant mortality can be explained on biological and economic grounds. For example, when fertility rates are relatively high, there may be relatively large percentage of high risk births. These include births to young mothers and old mothers, Eourth and higher-order births, illegitimate births, and low birth-weight births. Also, successive births in a relatively short period will weaken the mother and influence the physical constitution of children (Knodel 1968). Therefore, an infant born soon after the birth of a sibling is exposed to a higher risk of infant mortality because of the inadequate care of the physically weak mother during the critical period of infancy. Finally, based on economic reasons, 
parents with many children may allocate fewer resources, including their own time and purchased goods, to each child than parents with less children, ceteris paribus. Therefore, as Heer (1966) states, the more children per household the poorer their nutrition will be, ceteris paribus. Consequently, higher fertility in the household will result in higher infant mortality. This same argument can be also found in Malthus's "First Essay on Population."

All these above arguments give some apriori explanations of the direction of relationship between fertility and infant mortality. They do not, however, necessarily determine whether the researchers in this field treat the fertility rate and the infant mortality rate purely as either exogenous or endogenous variable in their models because population studies have not yet established dynamic relationships between fertility and infant mortality in a given system. 5

Section I descibes briefly the statistical technique of Granger's causality test and the statistical method to observe : dynamic relationships between variables. Section II reports the empirical results. Finally, section III gives a summary of the findings of this study. 


\section{STATISTICAL TECHNIQUES OF CAUSALITY TEST}

Granger (1969), Sims (1972), and Haugh (1976) have developed different statistical techniques to identify causality within a two-variable model. Their papers have sparked many empirical studies in the area of macroeconomics. 6

Granger (1969) defines causality between two stationary stochastic time series, $X(t)$ and $Y(t)$, within a set of information in the universe as follows: A time series $\mathrm{X}$ causes another time series $Y$ if the current value of $Y$ is more accurately predicted by using the information which includes at least the own-past series of $Y$ and the past series of $X$, than by using the information which excludes the past series of $x, 7$

According to my preliminary work, it is suggested that the time series of the fertility rate, $F(t)$, and the infant mortality rate, $M(t)$, be transformed to their stationary series, FE $(t)$ and MO(t); respectively, by using a logarithmic specification with no difference of the model and also by including a constant and a linear trend in equation. By following Granger's definitions (Granger 1969; and Granger and Newbold 1977), I estimate the following linear regressions of $F E(t)$ and MO(t) on lagged FEs and lagged MOs in a system: 8 


$$
\begin{aligned}
\widehat{F E}_{i}(t)=\widehat{a}_{0}+\sum_{s=1}^{m_{i}} \widehat{a}_{i}(s) F E_{i}(t-s) & +\sum_{s=1}^{n_{i}} \widehat{b}_{i}(s) M O_{i}(t-s) \\
& +\widehat{g}_{1} D 1+\widehat{g}_{2} D 2+\widehat{g}_{3} T, \ldots \\
\widehat{M O}_{i}(t)=\widehat{c}_{0}+\sum_{s=1}^{m_{i}} \widehat{c}_{i}(s) M O_{i}(t-s) & +\sum_{s=1}^{n_{i}} \widehat{d}_{i}(s) F E_{i}(t-s) \\
& +\widehat{h}_{1} D 1+\widehat{h}_{2} D 2+\widehat{h}_{3} T, \ldots .
\end{aligned}
$$

where $\hat{a}_{0}, \hat{a}_{i}, \widehat{b}_{i}, \widehat{c}_{0}, \widehat{c}_{i}, \widehat{d}_{i}, \widehat{g}_{i}$, and $\widehat{h}_{i}$ are the least-square estimates; the subscript, $i$, represents the $i-t h$ country; $\mathrm{m}_{i}$ and $\mathrm{n}_{i}$ are the lengths of lag distributions; $\mathrm{Dl}$ is a dummy variable for the period during World War II and D2 is a dummy variable for certain periods after the war; and $T$ is a linear time trend. 9

$$
\text { In order to identify the causality from } \mathrm{MO}_{i} \text { to } F E_{i}
$$
in equation ( 1 ), the null hypothesis is that the set of parameters $b_{i}(s), s=1,2, \ldots, n_{i}$, should be zero if there is no causality from $\mathrm{MO}_{i}$ to $\mathrm{FE}_{i}$. By the same manner, for the test of the causality from $F E_{i}$ to $\mathrm{MO}_{i}$ in equation (2), the set of parameters $d_{i}(s), s=1,2, \ldots, n_{i}$, should be zero if there is no causality from $F E_{i}$ to $\mathrm{MO}_{i} \cdot \mathrm{MO}_{i}$ in equation (1) and $F E_{i}$ in equation (2) are called causal variable in their respective equations. 
With respect to dynamic relationships between variables, Sims (1980) indicates that the estimated coefficients on successive lags in vector autoregressive models include complicated cross-equation feedbacks and, hence, the summing the distributed lagged coefficients is quite misleading. Instead, an alternative method is to estimate the moving average representation (MAR) in the system. 10

Consider an $q \times 1$ vector stationary stochastic time series $X(t)$ in the vector autoregressive representation (VAR) with a finite lag specification in a system, e.g., equations (1) and (2). Let $\widehat{x}(t)$ represent the best linear forecast of $X(t)$ based on its past series $X(t-s), s>0$. Then, the innovation in $x(t), V(t)$, is defined as

$$
v(t)=x(t)-\hat{x}(t)
$$

Given that $\hat{x}(t)$ is a linear combination of past values of $x(t)$, $V(t)$ is also a linear combination of current and past values of $x(t)$ for all $t$ and $V(t)$ is serially uncorrelated.

The general form of equation (3) is expressed as follows:

$$
G(L) X(t)=V(t) \text {, }
$$


where $G(L)=G_{0} L^{0}-G_{1} L^{l}-\ldots-G_{P} L^{P}$ and $L$ is the lag operator defined as $L^{l} X(t)=x(t-1)$. The $q x 1$ vector of variables in the system may be decomposed of an $m \times 1$ vector of endogenous variables - the fertility rate and the infant mortality rate, and an $n \times 1$ vector of exogenous variables - precipitation and temperature (Eckstein, Schultz, and Wolpin 1981).

After estimating the G's with appropriate lag distributions in equation $(4), X(t)$ in equation (4) can be expressed as a linear combination of innovations $v(t-s), s \geq 0$, i.e., the moving average representation (MAR) such as:

$$
x(t)=\sum_{s=0}^{\infty} F(s) v(t-s) .
$$

According to Sims (1978) and Eckstein, Schultz, and Wolpin (1981), if components of $\mathrm{V}$ are contemporaneously correlated, it is not possible to partition the variance of $\mathrm{x}$ into pieces accounted for by each innovation. Therefore, an orthogonalizing transformation to $\mathrm{V}$ in equation (5) is required to obtain $U(t)=T V(t)$, where $T$ is a lower triangular matrix with zero elements above the diagonal elements, to make the covariance matrix of $U(t)$ the identity matrix. 11 Then, equation (5) can be written as follows: 


$$
X(t)=\sum_{s=0}^{\infty} F(s) T^{-1} U(t-s) .
$$

Given the above equation (6), a particular i-th estimated equation of $x(t)$ in the form of MAR is expressed as follows:

$$
x_{i}(t)=\sum_{j=1}^{q} \sum_{s=0}^{k} f_{i j}(s) e_{i j}(t-s), \ldots \ldots
$$

where there are $\mathrm{q}(=\mathrm{m}+\mathrm{n})$ different components of $\mathrm{e}^{\prime} \mathrm{s}$. In this study, $\mathrm{q}=2$ : the innovation in fertility rate and the innovation in infant mortality rate. In equation (7), the sum of estimated coefficients of the $j-t h$ component of $f_{i j}(s)$ from $s=0$ to $\mathbf{s}=\mathbf{k}$ represents the cumulative responses in the $k+1$ step-ahead forecast of $x_{i}$, which is accounted for by the innovation in $x_{j}$. For the sign of association between fertility and infant mortality, I present the results of cumulative responses in three, five, and eight years ahead to an initial one-standard-deviation shock in innovation in infant mortality. 


\section{EMPIRICAL RESULTS}

\section{II-1. Granger's Causality Tests}

Granger's causality tests between fertility and infant mortality rates are performed using the annual data for the United States, the Netherlands, Japan, and Israel. After attempting different transformations of data and different lag distributions in the preliminary work, I present the logarithmic results of three lag distributions in equations (1) and (2).

Table II-l-1 contains the F-statistics on the three lag coefficients of the explanatory variables, fertility rate (F) " and infant mortality rate $(M)$, when fertility rate is the dependent variable and infant mortality rate is the causal variable. $M-F$ in this table represents the issue of causality from infant mortality to fertility under the null hypothesis that infant mortality does not cause fertility. Table II-1-2 contains the F-statistics on the three lag coefficients of the explanatory variables, infant mortality (M) and fertility (F), when $M$ is the dependent variable and $F$ is the causal variable. In this case, the issue of causality from $F$ to $M$ is tested under the null hypothesis that $F$ does not cause $M$.

Concerning the issue of causality from infant mortality to fertility in table II-l-l, we note that fertility is explained to a large extent by its own past history for these countries. 
Especially, the fertility behavior in the United states is significantly explained and dominated by its previous pattern. 12 The F-statistics on lagged coefficients of fertility is 201.6, which is much larger than those of the Netherlands, Israel, and Japan. On the other hand, the F-statistics under infant mortality (causal variable) indicate the significance in the causal relationship from $M$ to $F$. The results in the table show that there exists statistically significant causality at the conventional significance level for the Netherlands and Israel. The relatively large F-statistics of the Netherlands (9.893) and Israel (5.995) suggest that infant mortality is important in explaining the fertility behavior in these countries. In Israel, the infant mortality of its past history is as important as the fertility of its past history in explaining current level of fertility rate.

With respect to the issue of causality from fertility to infant mortality in table II-1-2, the infant mortality rates are well explained by their own past history in these four countries. Unlike the case of fertility, the own past history of infant mortality is less important in explaining itself in the United states, although the F-statistics on the three lagged coefficients of infant mortality is much larger than those of other countries. The test of causality from $F$ to $M$ in the table indicates that 
all results for these four countries are statistically significant at the conventional level. Above all, there are strong causal relationships from fertility to infant mortality for the United States and the Netherlands: the F-statistics are 8.419 and 7.440 , respectively.

As a summary of Granger's causality tests, we note that fertility and infant mortality are not mutually independent but significantly causally related with each other. In particular, both are jointly determined in the Netherlands and Israel. In other words, fertility and infant mortality are mutually interdependent in these countries. For the United States and Japan, there is significant unidirectional causality from fertility to infant mortality within a three-lag distribution in the system. 
TABLE II-1-1

Granger's Test of Causality: M - F

F-Statistics on Explanatory Variables

\begin{tabular}{lllll}
\hline Country & (d.f.) & Fertility & $\begin{array}{l}\text { Infant Mortality } \\
\text { (Causal Variable) }\end{array}$ & Time Period \\
\hline Netherlands & $(3,26)$ & $17.09 * * *$ & $9.893 * * *$ & $1939-174$ \\
Israel & $(3,23)$ & $6.907 * * *$ & $5.995 * * *$ & $1943-174$ \\
U.S.A. & $(3,47)$ & $201.6 * * *$ & 2.021 & $1923-179$ \\
Japan & $(3,19)$ & $4.680 * * *$ & 0.872 & $1950-177$ \\
\hline
\end{tabular}

Note. M-F represents the issue of causality from infant mortality
to fertility.

TABLE II-1-2

Granger's Test of Causality: F - M

F-Statistics on Explanatory Variables

\begin{tabular}{lllll} 
Country & $($ d.f.) & Infant Mortality & $\begin{array}{l}\text { Fertility } \\
\text { (Causal Variable) }\end{array}$ & Time Period \\
\hline Netherlands & $(3,26)$ & $17.43 * * *$ & $7.440 * * *$ & $1939-174$ \\
Israel & $(3,23)$ & $7.880 * * *$ & $3.831 * *$ & $1943-174$ \\
U.S.A. & $(3,47)$ & $37.15 * * *$ & $8.419 * * *$ & $1923-179$ \\
Japan & $(3,19)$ & $4.050 * *$ & $2.472 *$ & $1950-177$ \\
\end{tabular}

Note. F-M represents the issue of causality from fertility to infant
mortality.

(d.f.) is degrees of freedom.

* Significant at $a=10 \%$

** Significant at $a=5 \%$

*** Significant at $a=1 \%$ 
II-2 The Sign of Association between Fertility and Infant Mortality

Both fertility and infant mortality rates are expressed by

the fertility innovation and infant mortality innovation, which is the moving average representation (MAR) in the system. In this two-equation system expressed by MAR, the ordering of variables in the orthogonalization is infant mortality and fertility. I present the results of dynamic relationship in terms of the sign of association between fertility and infant mortality in table II-2-l.

The results in table II-2-l report that the cumulative responses in fertility and infant mortality to the innovations in infant mortality and fertility in three, five, and eight years ahead, respectively. In other words, those values under $M \rightarrow F$ are the sum of estimated coefficients of the infant mortality innovation, $\sum_{s=0}^{k} f_{i j}$ ' in estimating fertility, $x_{i}$, in equation (7), while those under $F \rightarrow M$ are the sum of estimated coefficients of the fertility innovation, $\sum_{S=0}^{k} f_{j}{ }^{\prime}$ in estimating infant mortality, $x_{j}$, in equation (7). First, with respect to the sign of $M \rightarrow F$, the values of empirically observed cumulative responses are negative almost for all time horizons shown. That is, typical random shocks in the infant mortality (a fall in $M$ ) will increase fertility above its normal level for these four countries except $k=5$ in Israel. In Israel, a fall in infant mortality will increase fertility 
above its normal level in three years and, however, will decrease fertility below its normal level in five years (see -0.50 at $k=3$ and 0.52 at $k=5$ under $M \rightarrow F$ in Israel). In general, the observed negative association, while not inconsistent with theory, is inconsistent with most previous research.

Second, with respect to the sign of $F \rightarrow M$, as usually hypothesized, the observed values of cumulative responses are positive at all time horizons shown except $k=3$ in Israel. Therefore, a fall in fertility will decrease infant mortality below its normal level. The positive asociation seems strengthened as the longer time horizon for the United States, the Netherlands, and Japan.

In addition to the above cumulative responses, when we closely look at the variation of infant mortality accounted for by its own innovation, we note that the variation in infant mortality in response to its own random shocks becomes quickly dampened in the Netherlands, reflecting non-negligible feedback effects from the fertility innovation to infant mortality in short periods. On the other hand, for other three countries, the variation in infant mortality generated by its own random shocks persists for a relatively long period in future. 14 
As a summary of the sign of association between fertility and infant mortality, I find that a reduction in fertility will decrease infant mortality below its normal level for all the countries, the United States, the Netherlands, Japan, and Israel, while a fall in infant mortality will increase fertility above its normal level for those four countries. The negative association in the latter, while not inconsistent with theory, is inconsistent with most previous research. 
TABLE II-2-I

Cumulative Responses in $\mathrm{K}$ Years Ahead to An Initial OneStandard-Deviation Shock in Innovation in Infant Mortality

\begin{tabular}{llcc}
\hline Country & $K$ & $M \rightarrow F$ & $F \rightarrow M$ \\
\hline \multirow{2}{*}{ Netherlands } & 3 & -6.71 & 4.86 \\
& 5 & -8.87 & 27.3 \\
& 8 & -13.7 & $108 . *$ \\
Israel & 3 & -0.50 & -0.27 \\
& 5 & 0.52 & 2.81 \\
& 8 & -2.37 & 1.48 \\
U.S.A. & 3 & -6.62 & 0.15 \\
& 5 & -12.4 & 1.34 \\
& 8 & -22.2 & 3.45 \\
Japan & 3 & -5.56 & 1.71 \\
& 5 & -11.5 & 2.86 \\
& 5 & -19.9 & 3.89 \\
\hline
\end{tabular}

Note. $M \rightarrow F$ represents the cumulative responses of fertility to infant mortality and $F \rightarrow M$ does the cumulative responses of infant mortality to fertility. * This cumulative response in 8 years ahead seems substantially large compared with those of other countries. Therefore, equations (1) and (2) with a first difference in logarithms are also estimated in Granger's causality tests. By using the obtained innovations in fertility and infant mortality rates, the cumulative responses are reestimated. However, there is no qualitative change, but the positive numerical value of the cumulative response in 8 years ahead is much smaller than the value presented above in the table. 


\section{SUMMARY}

The aims of this study are twofold: one is to empirically answer the question whether infant mortality is historically one of the significant factors which influenced fertility and vice versa; and another is to observe the sign of association between fertility and infant mortality.

By using a time series causality test developed by Granger, I have shown that fertility and infant mortality are not mutually independent but jointly determined. Also, in terms of the sign of association between fertility and infant mortality, I have shown that a reduction in fertility will decrease infant mortality below its normal level, while a fall in infant mortality will increase fertility above its normal level. 
FOOTNOTES

* Department of Economics, Brooklyn College of the city University of New York and National Bureau of Economic Research.

This paper is a product of my Ph.D. dissertation, sumitted to the Graduate School and University Center of the City University of New York. I am indebted to Professors Michael Grossman, Bernard Okun, Linda N. Edwards, Salih N. Neftci and my colleague, Mr. Tetsuji Yamada for their helpful comments on a draft of this paper. All errors in this paper are mine. Any opinions expressed are those of the author and not those of the institutions with which I am affiliated.

${ }^{1}$ williams (1975), p.l.
${ }^{2}$ see source of data in fertility rates discussed elsewhere.

3 The superstition, Hinoeuma, is that a woman born in that year is so aggressive that she eats men alive. This "Hinoeuma" comes every 60 years. See footnote 4 in Hashimoto (1974), p.226.

4 "The term "causally" in this paragraph is used in the sense of Granger's causality. This Granger's causality is explained in section $I$.

${ }^{5}$ Recent population studies by Lee (1981), and Eckstein, Schultz and Wolpin (1981) are some attempts to explore dynamic relationships among demographic, economic, and meteorological variables.

${ }^{6}$ For example, see Haugh (1976), Hsiao (1977), Mehra (1977 and 1978), Neftci (1978), Pierce (1977), Sims (1972), and William, Goodhart and Gowland (1976).

7 "Causality" in Granger's model means "linear causality between variables within a given set of information in a universe." See Granger (1969), p.430, and also Granger and Newbold (1977), p. 226.

${ }^{8}$ The causality test might be sensitive to misspecification, e.g., omitted variables or lag structure in the system. 
${ }^{9}$ The two dummy variables are used because the intercept might change for these different periods: Dl = 1 for 1936-1945 and $\mathrm{D} 1=0$ otherwise: $\mathrm{D} 2=\mathrm{I}$ for $1946-1950$ and $\mathrm{D} 2=0$ otherwise: in the United States, D2 = 1 for 1920-1926 and 1946-1955 and D2 = 0 otherwise; and in Japan, D2 = 1 for 1947-1956 and D2 = 0 otherwise.

${ }^{10}$ The rest of this section draws heavily on sims (1978 and 1980), and Eckstein, Schultz and Wolpin (1981).

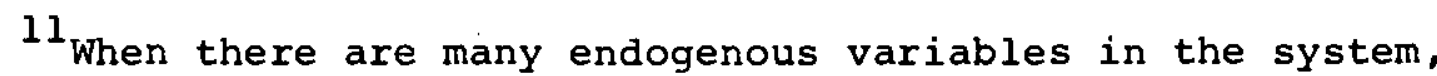
the ordering of variables for the triangular orthogonalization are an important issue (Sims 1978 and 1980).

12 When whites and nonwhites in the United states are separately treated, the results of Granger's causality tests are as follows:

Granger's Test of Causality: M - F

F-statistics on Explanatory Variables

$\begin{array}{lllll}\text { U.S.A. } & (\text { d.f.) } & \text { Fertility } & \text { Infant Mortality } & \text { Time Period } \\ \text { Whites } & (3,45) & 136.9 * * * & 2.241 * & 1923-177 \\ \text { Nonwhites } & (3,45) & 399.7 * * * & 0.754 & 1923-177\end{array}$

Granger's Test of Causality: F - M

F-statistics on Explanatory Variables

$\begin{array}{lllll}\text { U.S.A. } & (\text { d.f.) } & \text { Infant Mortality } & \text { Fertility } & \text { Time Period } \\ \text { Whites } & (3,45) & 32.10 * * * & 5.677 * * * & 1923-177 \\ \text { Nonwhites } & (3,45) & 15.80 * * * & 4.821 * * * & 1923-177\end{array}$

Note. M-F represents the issue of causality from infant mortality to fertility, while F-M does the other way around.

* Significant at $a=10 \%$

*** Significant at $a=1 \%$

${ }^{13}$ As a matter of space, although not shown in this paper, I find the same results in many Western European countries such as Finland, Italy, Norway, Switzerland and the United Kingdom. 


$$
\mathbf{F}-\mathbf{3}
$$

14 In equation (7), the sum of squares from $s=0$ to $s=k$ of the $j$-th component of $f_{i j}(s)$ represents the part of composition of error variance in the $k+1$ step-shead forecast $x_{i}$, which is ahead forecast (in the case of annual time series) error variance in $x_{i}$ due to typical random shocks of one standard deviation in the innovation in $x_{j}$ is expressed below by following Eckstein, Schultz and Wolpin (1981):

$$
p_{i j}^{2}(k)=\frac{\sum_{s=0}^{k} f_{i j}^{2}(s)}{\sum_{j=1}^{q} \sum_{s=0}^{k} f_{i j}^{2}(s)} \cdot
$$




$$
A-1
$$

\section{APPENDIX}

SOURCE OF DATA

U.S.A.: Historical Statistıcs of the United States, Colonial Times to 1970 , Bicentennial Edition. Part $19 / 1975$ U.S. Department of Commerce, Bureau of the Census Washington, D.C.

Statistical Abstract of the United States, looth Edition, 9/1979

U.S. Department of Commerce, Bureau of the Census Washington, D.C.

Monthly Vital Statistics Report, Provisional statistics: vol. 27, no.10, January 5, 1979; vol. 28, no.12, March 14, 1980; and vol.29, no.1, April 9, 1980.

the National Center for Health Statistics, U.S. Department of Health, Education, and Welfare Washington, D.C.

Japan : Japan Statistical Yearbook, various issues, especially the 28 th edition in 1978 .

Bureau of Statistics, office of the Prime Minister Tokyo, Japan.

Vital Statìstics 1975 (vol.1) and 1976 (vol.2) Japan.

Health and Welfare Statistics and Information Department, Minister's Secretariat, Ministry of Health and Welfare Tokyo, Japan.

Others: Demographic Yearbook, the lst issue(1948) - the 27th issue (1975).

Statistical Office of the United Nations, Department of Economic and Social Affairs, United Nations N.Y.

Statistical Yearbook, the 23rd issue(1972) - the 30th issue (1979).

Department of International Economic and Social Affairs, Statistical Office, United Nations N.Y. 


$$
A-2
$$

CHARACTERISTICS OF DATA

the Netherlands: Prior to 1949, villages of Elten and Tuddern are excluded. Rates include births occurring outside country if one or both parents are listed in

a Netherlands population register.

Israel

: Prior to 1946, rates are based on confinements resulting in live births of Jewish population.

Note. see Demographic Yearbook in detail.

DEFINITIONS

Fertility rate

U.S.A. : the number of live births per 1,000 female population between the ages of 15-44 years.

Others: the number of live births per 1,000 female population between the ages of 10-49 years.

Infant Mortality rate

All Countries : the number of deaths under 1 year (exclusive of fetal deaths) per 1,000 live births. 


\section{REFERENCES}

Becker, Gary S, and H. Gregg Lewis. "Interaction between Quartity and Quality of Children." In Economics of the Family, $e^{\prime}$. Theodore W. Schultz. Chicago: University of Chicago Press, 1974.

Butz, William P., Julie Davanzo and Jean-Pierre Habicht. "Biological and Behavioral Influences on the Mortality of Malaysian Infants." N-1638-AID. Santa Monica, Calif.: RAND Corp., April 1982.

Davis, Kingsley. "The World Demographic Transition." Annals of the American Academy of Political and Social Science, 237 , (January 1945): 1-11.

De Tray, Dennis N. "Child Quality and the Demand for Children." in Economics of the Fanily, ed. Theodore W. Schultz. Chicago: University of Chicago Press, 1974.

Eckstein, T. Paul Schultz, and Kenneth I. Wolpin. "An Analysis of Swedish Fertility and Mortality from 1790-1955."

Yale University, December 1981 .

Granger, C. W. J. "Investigating Causal Relations by Econometric Models and Cross-Spectoral Methods." Econometrica 37 no. 3 (July 1969): 424-438.

and Paul Newbold. Forecasting Economic Time Series. New York: Açademic Press, 1977.

Grossman, Michael, and Steven Jacobowitz. "Variations in infant Mortality Rates among Counties of the United States: the Roles of Public Policies and Programs." Demography, 21 no.4 (November 1981): 695-713.

Hashimoto, Masanori. "Economics of Postwar Fertility in Japan." In Economics of the Family, ed. Theodore W. Schultz. Chicago: University of Chicago Press, 1974.

Haugh, Larry D. "Checking the Independent of Two CovarianceStationary Time Series: A Univariate Residual CrossCorrelation Approach." Journal of the American Statistical Association 71 , no.354 (June 1976): 378-385.

Heer, David M. "Economic Development and Fertility." Demography 3 , no.2 (1966): 423-444. 
Heer, David M. and Dean O. Smith. "Mortality Level, Desired Family Sizes, and Population Increase." Demography 15, no.l (1968):

Hsiao, Cheng. "Money and Income Causality Detection." Cambridge, Massachusetts: National Bureau of Economic Research Working Paper No.167 (March 1977).

Japan. Japan Statistical Yearbook. various issues. Tokyo: Bureau of Statistics, Office of the Prime Minister.

- Vital Statistics 1975 and 1976. Tokyo: Health and Welfare Statistics and Information Department, Ministry of Health
and Welfare.

Knodel, J. "Infant Mortality and Fertility in Three Bavarian Villages: An Analysis of Family Histories from the 19th Century." Population Studies 22, no.3 (November 1968): 297-318

Lee, Ronald. "Short-term Variation: Vital Rates, Prices, and Weather." In The Population History of England 1541-1871, E.A. Wrigley and R.S. Schofield. Cambridge, Massachusetts : Harvard University Press, 1981.

Malthus, Thomas Robert. First Essay on Population. New York: St Martin's Press, $19 \overline{6} \overline{6}$.

Mehra, Y. P. "Money Wages, Prices, and Causality." Journal of Political Economy 85, no.6 (December 1977): $\frac{\text { Journal of }}{1227-1244 .}$

" Is Money Exogenous in Money-Demand Equations." Journal of Political Economy 86, no.2, Part 1 (April 1978): $211-228$.

Michael, Robert T. "Causation Among Socioeconomic Time Series." Paper presented at AER meetings, New York, (December 1977).

Neftci, Salih N. "A Time-Series Analysis of the Real WagesEmployment Relationship." Journal of Political Economy 86

Olsen, Randall J. "Estimating the Effect of Child Mortality on the Number of Births." Demography 17, no. 4
(November 1980): $429-443$.

Pierce, David. "Relationships-and the Lack Thereof-Between Economic Time Series, with Special Reference to Money and Interest nates." Journal of the American Statistical Association 72 ,

Preston, Samuel H., ed. The Effects of Infant and Child Mortality
on Fertility. New York: Academic Press, 1978. 
Sims, Christopher A. "Money, Income, and Causality." American Economic Review 62, (September 1972): 540-552.

- "Small Econometric Models of the U.S. and West Germany Without Prior Restrictions." Center for Economic Research, University of Minnesota, Discussion Paper 105

(December 1978).

"Macroeconomics and Reality." Econometrica 48, no.1, (January 1980): 1-48.

Taiwan. Statistical Yearbook of the Republic of China. The Republic of China: Directorate-General of Budget, Accounting \& Statistics, 1977, 1979.

United Nations. Demographic Yearbook. various issues, statistical Office of the United Nations, New York:United Nations.

- Statistical Yearbook. various issues, Statistical Office of the United Nations, New York: United Nations.

United States of America. Historical Statistics of the United States, Colonial Times to 1970. Bicentennial Edition. Part 1. Washington, D.C.: U.S. Department of Commerce, Bureau of the Cencus, 1975.

- Statistical Abstract of the United States. 100th Edition. washington, D.C.: Department of Commerce, Bureau of the Census, 1979.

- Monthly Vital Statistics Report, Provisional Statistics. Washington, D.C.: U.S. Department of Health, Education, and Welfare, vol.27, no.10 (January 1979); vol.28, no.12

(March 1980); and vol.29, no.1 (April 1980).

Williams, Anne Douglas. "Fertility and Reproductive Loss." Revised Paper. December 1975.

William, David, C.A.E. Goodhart and D.H. Gowland. "Money, Income, and Causality: the U.K. Experience." American Economic Review 66, no.3 (June 1976): 417-423.

Willis, Robert J. "Economic Theory of Fertility Behavior." In Economics of the Family, ed. Theodore W. Schultz. Chicago: University of Chicago Press, 1974.

Yamada, Tadashi. Causality between Infant Mortality and Fertility in Time Series. Ph.D. dissertation, the City University of New York Graduate Center, 1981. 